\title{
Health Promotion and Self- Management Among Patients with Chronic Heart Failure
}

\author{
Ying Jiang and Wenru Wang
}

\begin{abstract}
Heart failure is a chronic and complex clinical syndrome. It is one of the common causes of hospitalization and readmission among the older population. Patient self-management is essential to maintaining health and avoiding disruption of life caused by frequent hospitalizations. However, many patients lack selfcare skills. This chapter provides a review on evidence for the importance of selfmanagement and strategies to educate patients and promote self-care while living with the limitations on physical function.
\end{abstract}

\section{Keywords}

Health promotion $\cdot$ Self-management

Self-efficacy $\cdot$ Heart failure

\subsection{Introduction}

Heart failure (HF) is not a specific disease, but a chronic and complex clinical syndrome that developed as the end-result of a variety of cardiovascular diseases [1]. Broadly speaking, the car-

\footnotetext{
Y. Jiang $(\bowtie) \cdot$ W. Wang

Alice Lee Centre for Nursing Studies, Yong Loo Lin School of Medicine, National University of Singapore, Singapore, Singapore

e-mail: nurjiy@nus.edu.sg; nurww@nus.edu.sg
}

diac function of patients with HF may be impaired in two ways: (1) when cardiac contraction (ejection) is reduced and the heart is unable to pump the blood well, also known as "systolic dysfunction"; and (2) when relaxation of the ventricles is impaired and the heart is unable to fill the blood well, also known as "diastolic dysfunction." Both conditions lead to a decreased cardiac output which is insufficient to meet the body's metabolic demands [1], therefore, other compensatory mechanisms must be employed to offset the reduction in cardiac performance. These include activation of the neurohormonal and adrenergic pathways, as well as remodeling of the heart and blood vessels. The systemic and persistent overactivation of multiple neurohormonal and adrenergic pathways that aims at normalizing cardiac output may offer short-term benefits, but in a long run, the continued stimulatory effects on the heart will eventually worsen the HF progress [1]. Clinically, the typical symptoms of HF include symptoms caused by excessive fluid retention, such as dyspnea due to pulmonary congestion, abdominal distention from ascites, weight gain and peripheral edema, and symptoms caused by decreased cardiac output, such as activities intolerance, fatigue, hypotension, poor mentation, and weakness $[1,2]$.

As a chronic condition, HF imposes great burdens on the society. Around 38 million people worldwide are living with HF and the condition is becoming more common in both developing 
and developed countries [2-4]. The incidence and prevalence of HF increase with age. With the rising prevalence of cardiovascular risk factors, as well as improved survival rate in heart attacks and other cardiovascular diseases, the number of people with $\mathrm{HF}$ is expected to continue to surge $[5,6]$. The growing burden of HF is taking its toll on the society, particularly on the health care systems. HF is one of the most common causes of hospitalization and readmission [7-10]. In Singapore, age-adjusted HF hospital admission rate rose by 38\% from 1991 to 1998 [9]. More recently, local data from public institutions show that $\mathrm{HF}$ readmission rate is $18 \%$, with an average length of stay of 5.2 days per admission [11], which is similar to the average length of hospital stay (5-10 days) across the globe [2]. The lengthy and recurring hospital stays required by the patients not only account for the majority of health care expenditure but also pose additional challenges for hospital administrators to plan and allocate the scarce manpower and medical resources [7].

For the individuals, HF is a long-term condition that involves one or more hospitalizations. Living with HF is fraught with challenges. The distressing symptoms reduce the patients' independence and ability to perform many activities of daily living [12]. Also, recent health care reforms have increasingly shifted the selfmanagement responsibility to patients and families, as hospital stays are becoming shorter and less frequent. Therefore, the critical role of patients in their own care is receiving increasing attention. Self-care refers to specific behaviors that patients perform of their own accord to control their disease and maintain health [13]. As with many other chronic diseases, there is no cure for HF, but through treatment and self-care management, the impact on quality of life and disease progression can be abated.

The Salutogenic model of health considers health to be on a continuum between ease and dis-ease [14], instead of merely the absence of disease. Based on this model, most individuals are somewhere between the imaginary poles of complete wellness and complete illness [15]. An individual may have many physical ailments, but he or she can be relatively healthy if he or she is asymptomatic and fully functioning. Conversely, an individual who is physically healthy may also have moments of sickness or emotional distress. Health promotion requires the active participation of individuals in their contexts and, ultimately, moving towards the healthy pole [15]. To do this, individuals need to have the ability to understand the whole situation in which they find themselves, and to use the resources available to them to move in a direction that promotes health.

There are three key concepts in the Salutogenic model of health, namely, the generalized resistance resource (GRR), the specific resistance resource (SRR), and the sense of coherence (SOC) [16]. According to Antonovsky, GRR refers to an attribute of a person, a group, or a community that contributes to successfully coping with the inherent tensions of human existence $[16,17]$. In contrast, SRR is a specific resource used when a particular stressor is encountered [17]. GRR are resources with broad utility, such as wealth, ego strength, and social network, while SRR are resources with situation-specific utility, such as medical emergency number to access ambulance. Similarly, Sullivan [18] made a distinction between GRR and SRR and indicated that nursing is the GRR, while the nurse providing specific care to a particular health problem of the patient is the SRR. GRR is important for the development of a strong SOC [17]. Antonovsky [14] believed that a person with a strong SOC is more likely to mobilize the SRR and GRR in any given situation to overcome stressors. And through such a mechanism, SOC eventually translates into better health.

The concept SOC is a global life orientation, referring to a way of seeing the world as manageable, predictable and meaningful $[15,19]$. It consists of three essential components: "comprehensibility," "manageability," and "meaningfulness" [14]. SOC has a significant impact on health. In health promotion, SOC reflects a person's ability to identify their internal and external resources and use them in a way that promotes health and well-being [15]. Like personality, SOC is thought to be fairly stable and enduring, with only a margin of malleability [14]. The debate over 
whether SOC can be improved by interventions continues [20], but some have reported that the three components of SOC can be strengthened by interventions [21]. Nurses have a responsibility to promote patients' understanding of the situation after their diagnosis of HF (i.e. to increase patient's comprehensibility), to help patients reduce the adverse impacts of HF on their quality of life and to ensure patients are able to live as healthily as possible with their physical limitations (i.e. to improve manageability). Selfcare is an important part of promoting health in patients with HF. Despite its importance, many patients find it challenging, especially when transitioning from hospital care to home and community care $[22,23]$. Patients often feel unprepared to manage their condition in the community due to having to acquire a variety of skills in multiple domains of daily living without the supervision from hospital staff $[13,24]$. And many of these changes impose heavy demands on patients' ability to understand and act [13]. This chapter provides a review of some important research on $\mathrm{HF}$ self-management in the literature. Particular attention is paid to HF self-care and its associated problems, strategies to improve different aspects of HF self-care, as well as the multifaced psychosocial disease-management interventions to improve overall self-care management.

\subsection{Management of Heart Failure (HF)}

Overall, the aims of HF management are to (1) reduce morbidity, that is to reduce symptoms and hospital admissions while improving functional status and quality of life, and (2) to improve survival through slowing down the disease progression. In clinical practice, HF management generally includes treating the underlying causes of HF (e.g. coronary heart disease or valve disease) and associated conditions (e.g. hypertension or diabetes), follow-up monitoring and preventative care, case management and care coordination, patient education and support for self-management and health promotion, cardiac rehabilitation, palliative care, implantable device therapy, and in some cases heart transplantation $[25,26]$.

\subsubsection{Heart Failure Self- Management Interventions}

Self-management interventions refer to diseasemanagement interventions that focused on improving patients' self-care. Self-care is the cornerstone of HF management and health promotion, which defines as specific behaviors performed by a patient on his or her own accord to manage illness and maintain health [13]. Selfcare for $\mathrm{HF}$ encompasses a range of specific behaviors, from adhering to medication, reducing excessive fluid and salt intake, monitoring daily weight, exercising, monitoring and identifying exacerbating symptoms, and taking appropriate steps to intervene if symptoms worsened [27]. Studies have shown that if patients practice constant self-care, $30 \%$ of hospital admissions and more than half of the readmissions can be prevented [28, 29].

\subsubsection{Medication Management}

Medication is important in HF treatment. Most patients with HF are prescribed a combination of at least three types of agents: angiotensinconverting enzyme inhibitors (ACE-I), angiotensin II receptor blockers (ARB), $\beta$-blockers, aldosterone receptor antagonists (AA), and/or diuretics. Although evidences on medication efficacy are clear, studies have found that a significant proportion of patients does not take medication as prescribed [30]. In the literature, medication adherence rates vary widely, depending on how adherence is measured [30]. Zhang et al. [31] reported that on average, only half $(52 \%)$ of the patients had good medication adherence, which was measured by the ratio of total number of medication the patient had actually taken (numerator) over the total number of medication the patient should have taken (denominator). As medication regimens have become increasingly complex, many patients found medication management challenging. In the qualitative studies, patients reported that the demands to adhering the complex treatment regimens are onerous and difficult to meet. Some patients also reported troubles on learning new medications and dealing with the burden of medication side effects $[32,33]$. 
Previous studies on medication adherence have found an inverse relationship between number of daily doses and adherence rate [34, 35]. However, a recent study attempted to evaluate this strategy of simplifying medication regimen to once-daily dosing on its own did not find any evidence in improving medication adherence in patients with HF [36]. Specifically, there was no statistically significant difference in medication adherence between patients taking once-daily carvedilol controlled-release (CR) and patients taking twice daily carvedilol immediate-release (IR) for a 5-month period. However, this trial may be confounded by the "ceiling effect" resulted from high baseline medication adherence among the participants [36]. In addition, in a systematic review on the relationships between dosage regimens and medication adherence, Claxton et al. [37] compared medication adherence between different dose regimens and found that medication adherence was significantly higher with once daily regimens compared to 3-times-daily or 4-times-daily regimens, and between twice-daily dosing and 4-times-daily dosing. However, there was no significant differences in medication adherence between oncedaily and twice-daily regimens or between twice-daily and thrice-daily regimens [37]. These findings suggest that simpler medication regimens may improve patient's medication management and medication adherence, but that simply reducing a single dose (e.g., from twice-daily to once-daily) may have too little impact on patients.

Two systematic reviews have reviewed intervention strategies to promote medication adherence in HF patients [38, 39]. Overall, more than half of the included studies $(63 \%$ and $50 \%)$ shown significant better medication adherence in the intervention arms, suggesting that medication adherence in patients with HF can be improved by effective interventions. Because of the importance of comprehensibility in building SOC and promoting health [40], effective interventions should not only increase patient knowledge of medications, but also be delivered in a way that is easy for patients to grasp. In the literature, most of the effective interventions used a combination of educational, behavioral, and affective inter- ventions, with education being the most widely included component [38]. Studies using intensified patient care included interventions with direct patient contacts and interventions with regular telephone follow ups or tele-monitoring. Face-to-face direct patient contacts were found to be the most effective strategy in improving mediation adherence. In contrast, only one of the telephone-based or tele-monitoring interventions has led to enhanced mediation adherence [39]. Similar result was observed in a recently published systematic review and meta-analysis of the effectiveness of mobile phone-based selfmanagement interventions on medication adherence in patients with coronary heart disease [41]. In this review, the meta-analysis result from the pooled data did not find a significant impact of the mobile phone-based interventions on improving medication adherence [41].

More recently, mobile health (mhealth) applications (apps) to support medication adherence have also grown in number, some studies have been conducted to examined its efficacy among cardiovascular patients, including patients with HF [42, 43]. Goldstein et al. [42] performed a four-arm randomized feasibility study of 60 participants with HF, comparing an e-pill box (telehealth) to a smartphone-based mHealth app on medication adherence and patient's acceptance of the devices. Participants were provided one of the two devices with or without active reminders. No significant difference in medication adherence was found among the four arms. However, patients preferred the mHealth approach [42]. Studies conducted on other cardiovascular patients showed modest benefits in improving medication adherence [43].

Taken together, current evidences suggest that multicomponent interventions conducted face to face may still be the most effective strategy to improve medication adherence in patient with HF. Although some evidences suggests that mHealth app may potentially improve medication adherence in patients with cardiovascular diseases, findings from trials on patients with $\mathrm{HF}$ are not consistent. High-quality trials are still needed to confirm its role and justify its use in routine care [43]. 


\subsubsection{Sodium Restriction}

Restricting daily sodium intake to $<2 \mathrm{~g}$ has been commonly recommended in patients with HF. However, there is no firm evidence to support this practice [44]. Both observational and experimental studies have shown mixed results [45-47]. Therefore, the efficacy and safety of sodium restriction remain unclear, and there is no consensus on the optimal amount of sodium intake for patients with HF [48]. Updated guideline by the Canadian Cardiovascular Society has recommended patients with $\mathrm{HF}$ to restrict their daily dietary salt intake to between 2 and $3 \mathrm{~g}$ [49], while the recent American College of Cardiology Foundation (ACCF)/AHA guideline for $\mathrm{HF}$ management suggests some degree of sodium restriction (e.g. $<3 \mathrm{~g} /$ day) in patients with congestive symptoms but does not endorse any specific level of sodium intake [50]. Similarly, the 2016 European Society of Cardiology (ESC) guideline for diagnosis and treatment of HF does not provide any explicit recommendation on sodium restriction but suggesting avoiding excessive salt intake ( $>6 \mathrm{~g} /$ day) [51]. Most of these recommendations are based on expert opinions given the conflicting evidences in the literature, which make it difficult to compare or draw definite conclusions [50, 52-54].

In the context of HF self-care, adhering to a low-sodium diet requires patients to understand the relationship between sodium intake and congestive symptoms (e.g. edema), and make sensible adjustments to their diet based on clinical situation [49]. To do this, the patient would need to have the knowledge and skills to measure daily sodium intake, know how to read food nutrition labels, distinguish low-sodium foods from highsodium foods, and recognize the "hidden" sources of sodium (e.g. canned foods). In addition, patients are also required to perform actions of choosing low-sodium food and avoiding highsodium food, reducing salt added in cooking, as well as asking for reduced-salt meal when eating out at restaurants [55]. Therefore, dietary adherence is often difficult.

It was reported that HF patients had an average of 2.7-3.9 $\mathrm{g}$ daily sodium intake as measured by $24-\mathrm{h}$ urine sodium [56]. Riegel et al. [57] reported that medication adherence was the highest $(95.5 \%)$, while dietary adherence $(45.5 \%)$ was the lowest after hospital discharge, and overtime, both adherences decreased rapidly. Within 3 months, the overall adherence rate for lowsodium diet was $42 \%$, compared to $96.4 \%$ for adhering to fluid restriction and $84.7 \%$ for adhering to medication [57]. Colin-Ramirez et al. [58] evaluated the dietary patterns of sodium consumption in 237 patients with HF. It was reported that $4.2 \%$ of patients who reported "always" being adherent with a low salt diet ate canned or package soups daily, while $22.9 \%$ of those who reported "sometimes" being adherent ate fast foods one to three times a week. Among all the participants, one third (30\%) reported consuming large amounts of processed meat on a weekly basis, and 52\% reported using seasoning such as ketchup, BBQ sauce, soy sauce, or salad dressings in their cooking. On further examination, a number of the participants connected the idea of low-salt diet mainly with not adding salt to cooking, but not with reducing high-sodium processed foods. Similarly, in an earlier study, Chung et al. [59] found that there was no significant difference in the 24-h urine sodium levels between those who reported being adherent to low-sodium diet $(4560 \mathrm{mg}$ ) and those who reported being nonadherent (4333 mg, $p=0.59$ ). The inconsistent findings between self-reported adherence and participants' actual dietary pattern on sodium intake reflected significant gaps in patients' knowledge related to low-sodium diet [59], even when dietary teaching on low-sodium diet was provided to all the participants by a registered dietician [58].

A qualitative study exploring factors associated with not adhering to low-sodium diet has found that "lack of knowledge," "interference with socialization," and "lack of food selections" were the major reasons contributing to nonadherence [60]. Many patients perceived that health care providers did not cover what they wanted to know, and they were given too little information on low-sodium foods or strategies to follow dietary recommendations. For patients with additional dietary restriction, following a dietary regimen can be confusing, and confounded by the 
limited food choices, for example, patients with diabetes worried that eating fresh fruits that contained low sodium may increase their blood glucose levels [60]. Similarly, in a descriptive study, Ong et al. [61] reported that although patients may understand their diet restriction, but they faced practical problems because of limited food choices and lack of tactics to fit the dietary regimen into their everyday lives.

While health care professionals believe the importance of patient education [62, 63], such belief does not seem to be translated into promoting patients' knowledge or self-care. Riegel et al. [57] observed that although nurses routinely teach patients about importance of treatment adherence and behaviors that are important to adopt, adherence to self-care recommendations decreased rapidly after hospitalization. The finding called into question whether patient education during hospitalization is effective in influencing patients' adherence. Similarly, Bentley et al. [60] raised the question of whether patients truly did not receive diet education, or whether the education delivered was untimely, ineffective, and presented in a way that hinders learning. Some studies have suggested that effective teaching should be provided over several sessions to increase knowledge retention [62]. In addition, it is important to involve family member as their understanding of low-sodium diet may enhance patient's adherence and reduce family conflict [64]. Repetitive reinforcement of diet guidelines seems to have little effect on promoting dietary adherence [61], therefore, interventions would also need to address factors other than lack of knowledge [60].

\subsubsection{Fluid Restriction}

The 2013 ACCF/AHA and the 2016 ESC HF guidelines have suggested fluid restriction of $1.5-2 \mathrm{~L} /$ day in patients with refractory or symptomatic HF to relieve congestion [50, 51], and it is best implemented in the context of selfmanagement on symptoms and weight monitoring. Routine fluid restriction in all HF patients regardless of symptoms or other considerations does not show any benefits, therefore it is not recommended [50].
In a recent review on fluid restriction in patients with HF, Johansson et al. [65] found that most of the randomized trials included fluid restriction as one of the components in combined intervention, only two studies assessed the effect of fluid restriction alone [66, 67]. But neither of them found any significant differences in clinical parameters, body weight, or renal markers between patients on fluid restriction and those with a liberal fluid intake [66, 67]. Many of the studies did not report patients' actual fluid intake, but studies did report on this showed most of the patients consumed less than 2 L/day, irrespective of whether they were in the intervention group or control group, suggesting that excessive fluid intake may not be a general problem in the HF population [65-67].

On the contrary, stringent fluid restriction in hot and low-humidity climates may predispose patients with HF to heat stroke [50]. It was also reported that fluid restriction of $1.5 \mathrm{~L} /$ day was associated with decreased quality of life and increased sensation of thirst [66]. Elderly patients might even be at risk of dehydration as a result of impairment of thirst sensation, decreased kidney function, medications (e.g. diuretics), depression or dependence on a caregiver to provide fluid [68]. Therefore, the discussion of fluid intake should be placed in a larger context of HF management with consideration of dietary habits, diuretic regimen, and symptoms presentation rather than restricting fluid intake in isolation [66]. In HF self-care, fluid management also requires patients to recognize the needs to alter fluid intake, such as to increase fluid intake during period of high heat, nausea, or vomiting, and to restrict fluid when body weight increases and/ or presence of congestive symptoms [50,51].

\subsubsection{Daily Symptoms Monitoring}

Changes in signs and symptoms often precede further changes in clinical status that may require intervention. For example, weight gain is commonly regarded as a marker of HF decompensation. In a nested case-control study among 268 patients with HF, Chaudhry et al. [69] reported that weight gain was associated with a subsequent hospitalization for $\mathrm{HF}$ and started at least 1 
week before admission. Daily monitoring of signs and symptoms is a pragmatic way for patients to track their health status and identify high-risk period, during which timely interventions could be rendered to avert episodes of decompensation. Major clinical guidelines have recommended symptoms monitoring as part of the routine self-care management, specifically, daily weight monitoring, daily check for edema, and daily check for symptoms severity are the typical self-care strategies to monitor signs and symptoms $[55,70]$.

Despite the importance of symptoms monitoring, Zeng et al. [63] reported that HF patients lacked the knowledge on HF symptoms recognition. Among 187 Singaporean HF patients, only $55.6 \%$ were able to associate increased weight with change in HF condition, and less than half $(40.1 \%)$ knew that they should weigh themselves every day. More than half of the patients were not able to recognize signs and symptoms of worsening HF [63]. Similarly, Ong et al. [61] investigated the learning needs among hospitalized Singaporean patients with $\mathrm{HF}$ and found that education topics on HF signs and symptoms were ranked as the most important learning need by the patients. These findings echoed the result of an earlier qualitative study that local patients wanted to know more about their conditions and symptom management, but physicians preferred to discuss their conditions with their family more than with them. Consequently, patients felt less empowered to manage their conditions [71].

Studies conducted in other countries found similar challenges in symptoms monitoring and detection [13, 72-74]. Moser et al. [75] reported that symptoms monitoring was the least wellperformed self-care activities, with only $14 \%$ weighing themselves every day and $9 \%$ monitoring for symptoms of worsening HF. Adequate self-monitoring and symptoms management impose heavy demands on patients' ability to understand and act on their knowledge. However, poor memory on basic concepts of HF, misattribution of symptoms to other conditions, and low comprehension of links between symptoms and $\mathrm{HF}$ are common among patients [72]. Older patients often discount the early-warning signs as normal aging [76, 77]. Some evidences have reported that $\mathrm{HF}$ is associated with changes in cognitive function, therefore diminishing patients' ability on symptoms perception [78, 79]. Furthermore, inadequate explanation by the health care professionals is perceived as another barrier. Even when patients are provided with educational brochures, they do not feel sufficiently informed [24]. Most of the patients are not ready to receive education at the time of initial diagnosis due to the fears and worries stemming from the new diagnosis of HF. On the other hand, education given at the time of hospital discharge is often overwhelming and hard to follow, especially when a big chunk of information needs to be communicated to the patient at one go [80]. Consequently, the windows of opportunity to treat the early symptoms of HF decompensation may be hindered by the difficulties that patients faced in monitoring and recognizing the symptoms [81]. Therefore, strategies to improve the "comprehensibility" and "manageability" in symptom monitoring remain essential. For example, comprehensibility can be supported by teaching patients on how to make sense of their subjective symptoms (e.g. feeling of fatigue) and objective assessment (e.g. weight record and edema assessment), providing easy-to-understand graphic illustrations, and breaking down information into digestible chunks by using simple language and short sentences. Manageability can be improved by providing technical solutions on how to incorporate symptom monitoring into the patient's daily routine.

Similar to medication management, interventions based on remote telemonitoring, mobile phone-based monitoring and mHealth apps have grown significantly in the field of symptoms monitoring over the past two decades [82]. The deployment of these technologies has provided a powerful tool to look for early warning symptoms and to prevent hospitalization [83]. However, evidences from the literature show inconsistent results on the effectiveness of these technologies.

In an earlier Cochrane systematic review and meta-analysis, Inglis and colleages [84] reported that remote telemedical surveillance through 
telemonitoring significantly reduced all-cause mortality (RR 0.66 , 95\% CI $0.54-0.81$ ) and HF-related hospitalizations (RR 0.79, 95\% CI 0.67-0.94). "Structured telephone support" by using a mobile phone to monitor symptoms and provide self-care management without additional home visit or intensified clinic follow-up significantly reduced HF-related hospitalizations (RR $0.77,95 \%$ CI $0.68-0.87$ ), although effect on reducing all-cause mortality was not statistically significant (RR 0.88, 95\% CI 0.76-1.01) [84]. In another study, Seto and colleagues [85] tested the effect of a mobile phone-based telemonitoring system on the outcomes of HF patients after a decompensation episode. The mobile phonebased patient terminals were used for data collection and data transmission. Patients in the intervention group were required to have their weight and blood pressure measured daily, single-lead ECG measured weekly, and to answer symptoms check questions on their mobile phones daily for 6 months. Their results showed that participants in the intervention group had significant improvements in self-care maintenance and HRQoL compared to those in the control group after 6 months. However, differences on the hard outcomes, such as hospitalization, mortality, or emergency department visits between the two groups were not significant [85]. Similarly, in a large-scale RCT (the Tele-HF study) involving 1653 patients with HF, Chaudhry et al. [86] testing out a telephone-based interactive voice response (IVR) system that gathered information on symptoms and weight every day, but failed to show any evidence on improving patients' clinical outcomes. Furthermore, the study found that $14 \%$ of the patients in the intervention group never used the system, while only $55 \%$ of them were using the system at least three times a week. The authors believed that the adherence rate reflected the "best case" scenario which is difficult to replicate in the real-world clinical practice since considerable resources were directed toward optimizing patients' engagement in this clinical trial [86]. The trial by Scherr et al. [83] also reported low adherence rate that $22 \%$ of their study participants were "never beginners" due to the difficulty in entering and sending the data through a mobile phone internet browser.

Many of the technologies being tested in the previous studies are almost obsolete today due to how rapidly technology is changing. For example, in the Tele-HF study, participants needed to call the IVR system daily [86], while in the other two studies, the study interventions were based on the old mobile phone models (BlackBerry Pearl 8130 and Nokia 3510) for data transmission and symptoms reporting [83, 85]. The less user-friendly patient terminal may decrease the usability of an intervention, especially for those elderly and technically unskilled patients [83]. More recently, with the rapid development of mobile technology and the expansion of mobile network coverage, personal mobile devices (smartphone and/or tablets) and mHealth apps seem to be better positioned for monitoring symptoms [82]. In a single-arm prospective pilot study, Zan and colleagues [87] evaluated the feasibility of a remote web- and telephone-based monitoring system, called the "iGetBetter" system. The "iGetBetter" system enables the patients to self-monitor their body weight by a bluetooth weight scale and blood pressure through an auto-inflating blood pressure cuff. Data were transmitted onto the secured web platform. Patients can view their results by logging into the patient portal using an iPad mini at home, while the physician can access patients' data remotely through the clinician portal. Patients who did not complete the self-monitoring activities as planned would receive a reminder phone call from the IVR telephone system. The IVR telephone system served as an alternative means for patients to log their activities and key in their measurements manually through the phone keypad. Over the 90-day study period, the study team found that 19 patients $(95 \%)$ agreed that the monitoring system was easy to use, and more than half of the participants had $80 \%$ or greater adherence to care plan. Most participants engaged the system through patient portal on the iPad mini, but three participants (15\%) only used the IVR telephone system exclusively. At the end of the study, participants had an improvement of HRQoL from baseline, but there were no significant differences in hospital utilization and length 
of hospital stay [87]. The pilot study demonstrated the feasibility of a remote monitoring system that leveraged on latest mHealth technology and portable digital devices. It offered a potential lowcost solution on timely symptoms monitoring [87]. However, its effect on clinical outcomes were yet to be confirmed. To date, there is still a lack of evidence from high-quality large-scale randomized controlled trial (RCT) on clinical effectiveness of these technologies [55].

\subsubsection{Other Lifestyle Modifications}

Physical inactivity, cigarette smoking and excessive alcohol consumption are the highly avoidable lifestyle risk factors for worsening HF. Therefore, exercise, smoking cessation and limit alcohol intake are the other recommended self-care strategies.

Many studies have demonstrated consistent benefits for a range of outcomes with exercise training in patients with HF, including improved quality of life, improved functional capacity, decreased mortality and reduced hospitalization [88-90]. Exercise training or regular physical activity is the Class I recommendation to improve functional status among patients with HF according to the 2013 ACCF/AHA guideline [50]. Nonetheless, exercise adherence is hard to maintain. Some studies reported that overall exercise adherence rate ranged from $9 \%$ to $53 \%$ [13]. In a large RCT with 2331 stable HF patients (the HF-ACTION trial), exercise adherence of the participants in the intervention group decreased over time, from a median of 95 min per week during 4-6 months follow-up to 74 min per week during 10-12 months follow up, even though the patients were provided a structured exercise program and were supervised closely [88].

Smoking and excessive alcohol consumption are associated with higher risk of HF mortality in patient with HF [91, 92]. Smoking cessation is as effective as drug treatment in reducing mortality among smokers with HF, with benefits of prevention death and hospitalization emerging quickly in less than 3 years $[91,93]$. Therefore smoking cessation is an important part of HF self-care and should be encouraged in all HF patients who are current smokers [55].
Earlier guideline has stated that patients with HF should limit their alcohol intake to two standard drinks or less per day for men and one standard drink or less per day for women, while patients with suspected alcohol-induced cardiomyopathy should abstain from alcohol [94]. More recent guidelines only recommend counseling and/or treatment to reduce alcohol intake in patients who have consumed excessive amounts of alcohol, especially in patients with alcoholinduced cardiomyopathy [50, 51]. It should be noted, however, that the effects of small amounts of alcohol are still controversial $[95,96]$. Therefore, for those who were nondrinkers, health care provider should not endorse alcohol to them [97].

In summary, HF self-care consists of a variety of skills across multiple domains on a daily basis $[13,72]$. It is a dynamic and complex process, in which some of the required actions may conflict with patients' preferences. Despite its importance, HF self-care remains challenging for many patients. While several studies focus exclusively on improving a single aspect of HF self-care, such as medication management or symptoms monitoring, most studies adopt a multifaceted approach to improve patient's overall self-care management. The following section will provide a review on these interventions.

\subsection{Psychosocial Self- Management Interventions}

In the literature, there are many disease management programs developed to help patients to manage their HF condition and to improve overall self-care and promote health [88, 98-102]. Most of these programs are instructional with a focus on the value of exercise training, pharmacological care and lifestyle modifications [88, 98, 99, 102, 103]. While evidences acknowledge that patient education is a necessary and important component to promote effective self-care [104106], it is also noted that education alone is insufficient to support behavioral changes [107]. Efforts to promote successful self-care should consider patients' knowledge, skills and engagement [55]. 
Over the past decades, there has been increasing attention to the role of psychosocial factors in the etiology and prognosis of cardiac disease, including HF [108, 109]. Psychosocial interventions, as part of the nonpharmacological interventions, have been increasingly used to enhance the health outcomes of patients with HF [110]. Besides disease education, a psychosocial education program is usually an intervention that combines psychological (e.g. cognitive behavioral therapy, relaxation, motivational interviewing, nondirective counseling, or supportive therapy) and social (e.g. social support) components. It is a multicomponent intervention that aims to promote patients' understanding of knowledge and encourage behavioral changes for an effective self-management [111]. It is also a holistic approach to improving health literacy, strengthening a person's psychological and social resources, enabling patient's resistance to illness, and mitigating the negative impacts of HF on their quality of life.

In a recent systematic review and metaanalysis, Samartzis et al. [110] examined the effectiveness of psychosocial interventions on quality of life in patients with HF. The review included 16 RCTs involving 2180 participants. The combined data showed that psychosocial interventions improved patients' quality of life (standardized mean difference [SMD] 0.46, 95\% CI 0.19-0.72), among which, face-to-face interventions showed greater quality of life improvement compared to telephone-based interventions $(p<0.02)$. However, in terms of length of the intervention, or whether the intervention adopted a multidisciplinary team approach, or whether used telemedicine technology, or whether involved patients' caregivers in the intervention, there was no evidence favoring any specific type of these psychosocial interventions. In addition, education on disease aspects and/or psychoeducation were presented in most of the interventions, which are often given by a nurse, suggesting that patient education still played a significant role in improving patients' quality of life [110].

Patient engagement plays a pivotal role in designing an effective self-management intervention. Without patient's engagement, knowledge and skills are less effective to enhance HF selfcare [55]. Psychological techniques, such as motivational interviewing techniques and cognitive behavioral strategies, may improve patients' engagement and psychological outcomes. However, the effect of psychological intervention on self-care and psychological outcomes among patient with HF are less clear. An earlier Cochrane systemic review and meta-analysis on psychological intervention for depression in patients with HF found no studies that met their inclusion criteria [112]. Although a later systemic review and meta-analysis supported the efficacy of some psychological interventions, such as psychotherapy, progressive muscle relaxation techniques, counselling or mindfulness-based intervention in improving psychological outcomes among patients with coronary heart disease, but none of the included studies was conducted on patients with HF [113]. Our recent systematic and metaanalysis on the efficacy of psychological interventions on self-care, psychological and health outcomes in patients with HF has found that psychological interventions improve health-related quality of life at 3 months of follow-up [114]. However, there was no statistically significant effect detected after 3 months of follow-up. The intervention effects on the participants' anxiety level was not statistically significant. In addition, evidences from appraised literature revealed possible positive but short-term effects on HF selfcare. Cognitive behavioral therapy tends to improve depression levels [114].

As one of the psychological factors, SOC refers to one's enduring attitude towards life, which is the basis for successfully coping with life's ups and downs. It is also thought to motivate individuals to stay healthy during the trajectory of a worsening illness [115, 116]. Gallagher [116] reported that a strong SOC is one of the predictors for better self-management in patient with HF living in the community. However, Ferreira and colleagues [117] did not find any significant difference in SOC in relation to performing any self-care behavior or not among hospitalized HF patients. Other studies have suggested that SOC may associate with better HRQoL and life satisfaction in patients living 
with HF [115, 118]. Nevertheless, after searching the literature, it was found that there is still a lack of studies in the literature to date on the effectiveness of interventions based on the Salutogenic approach or the concept of SOC in improving self-management of HF.

\subsection{1 mHealth-Based Multicomponent Self- Management Intervention}

Most recently, with rapid evolution of technology over the past few decades, there has been an increasing trend in using mHealth to promote chronic disease self-management in the literature [119-121]. There is evidence suggesting that mHealth offers prospects for providing effective and affordable health care services to a widespread population, reducing geographical inconvenience and socioeconomic disparities [119]. In HF self-management, mHealth provides a new way to improve patient participation in self-care by constantly reminding patients about key aspects of self-care and symptoms tracking [122]. Compared to the older technology, the newer generation of personal mobile devices (smartphone and/or tablets) and mHealth apps also have better usability and integration into patient's everyday lives [82]. Therefore, it has a great potential to be adopted in the multifaceted HF self-management.

Nevertheless, as aforementioned, many of the initial mHealth technologies are deployed to primarily support a single aspect of HF self-care, such as medication management or symptoms monitoring. There are very few studies on mHealth-based interventions aimed at improving overall self-care, even though the number of commercially available mobile apps is growing rapidly [123]. In the most recent study, Athilingam and her team [124] have developed a new smartphone app (the HeartMapp) to improve overall self-care and quality of life in patients with HF. The smartphone-based intervention leveraged on mobile phones and heart rate sensor (chest strap) to provide individualized alerts on symptom checking, symptom management and medication adherence, as well as real-time vital signs monitoring. The components of the HeartMapp app covered all the essential aspects of HF self-care, including patient education, medication management, symptoms monitoring and management, relaxation technique (deep breathing exercise), and physical activity (walking) [124]. Their results revealed that participants in the HeartMapp group had significant improvement in self-care management, self-care confidence, and HF knowledge. But results on medication adherence, quality of life, and depression were not significant. Over 30-day study period, $43 \%$ (4/9) used the app daily and completed daily symptoms assessment and exercise, $56 \%$ (5/9) accessed HeartMapp features over $80 \%$ of the time (24/30 days). However, the study attrition rate was close to $30 \%$ [124], which was higher than previous studies adopting a face-toface multicomponent psychosocial educational disease management approach [110]. The small sample size and high attrition rate has limited the generalizability of their findings [124]. In addition, the review of existing commercially available apps for HF self-care management has found that very few apps met the prespecified criteria for quality, content, or functionality. Therefore, these findings underscore the need for further clinical validation and mapping evidence-based guidelines to improve the overall quality of selfcare-related apps [123].

\subsection{Conclusion}

In summary, this chapter provides a review of research on HF self-management interventions aimed at improving self-care and promoting health. HF is a disabling and life-limiting condition. Living with HF is challenging, with many patients expressing frustration when they were unable to perform their daily work or social roles due to symptom burden or decreased physical function. Effective self-management may help to stabilize their life while living with the limitations on functional abilities and disease burden.

Today, the medical perspective and approaches are highly developed and emphasized, which is 
good. However, patients are whole human beings, a person consisting of different dimensions; individuals comprise of a wholeness of body-mind-spirit. Thus, a holistic physical-psychological-social-spiritual model of care is required in order to provide high-quality and effective health care. The health care industry still largely follows a pathogenesis paradigm. Integrating and applying salutogenesis into specific disease management can be challenging. The successful application of salutogenesis in this area cannot accomplished by only introducing it into the clinical practice, but it has to demonstrate its evidence-based properties. Therefore, research in this area is still very much needed if the salutogenic model of health is to gain greater acceptance in the health care field [17].

\section{Take Home Messages}

- Heart failure is a chronic, disabling, and lifelimiting condition. The Salutogenic model of health focuses on the origins of health and emphasizes efforts towards health promotion.

- Effective self-management and self-care skills help patients to stabilize their life while living with the limitations on functional abilities (i.e. moving towards the healthy pole).

- Heart failure self-care required skills across multiple domains of life. Many patients find it difficult to manage.

- Effective interventions should be multifaced and adopt a holistic approach to improve patients' health literacy and strengthen their psychological and social resources.

- Nurses play a significant role in empowering patients to self-manage their condition and move in the health-promoting direction.

\section{References}

1. Krum H, vod Lueder T. Advances in heart failure management. London: Future Medicine Ltd; 2012.

2. Ponikowski P, Anker SD, AlHabib KF, Cowie MR, Force TL, Hu S, et al. Heart failure: preventing disease and death worldwide. ESC Heart Fail. 2014;1(1):4-25.

3. Heidenreich PA, Trogdon JG, Khavjou OA, Butler J, Dracup K, Ezekowitz MD, et al. Forecasting the future of cardiovascular disease in the United
States: a policy statement from the American Heart Association. Circulation. 2011;123(8):933-44.

4. Reyes EB, Ha JW, Firdaus I, Ghazi AM, Phrommintikul A, Sim D, et al. Heart failure across Asia: same healthcare burden but differences in organization of care. Int J Cardiol. 2016;223:163-7. https://doi.org/10.1016/j.ijcard.2016.07.256.

5. Rajadurai J, Tse HF, Wang CH, Yang NI, Zhou J, Sim D. Understanding the epidemiology of heart failure to improve management practices: an AsiaPacific perspective. J Card Fail. 2017;23(4):327-39. https://doi.org/10.1016/j.cardfail.2017.01.004.

6. Richards AM, Lam C, Wong RC, Ping C. Heart failure: a problem of our age. Ann Acad Med Singap. 2011;40(9):392-3.

7. Bundkirchen A, Schwinger RHG. Epidemiology and economic burden of chronic heart failure. Eur Heart J Suppl. 2004;6(Suppl D):D57 LP-D60. http://eurheartjsupp.oxfordjournals.org/content/6/suppl_D/ D57.abstract.

8. Kannel WB. Incidence and epidemiology of heart failure. Heart Fail Rev. 2000;5(2):167-73. https:// doi.org/10.1023/A:1009884820941.

9. Ng TP, Niti M. Trends and ethnic differences in hospital admissions and mortality for congestive heart failure in the elderly in Singapore, 1991 to 1998. Heart. 2003;89(8):865-70.

10. Santhanakrishnan R, Ng TP, Cameron VA, Gamble GD, Ling LH, Sim D, et al. The Singapore heart failure outcomes and phenotypes (SHOP) study and prospective evaluation of outcome in patients with heart failure with preserved left ventricular ejection fraction (PEOPLE) study: rationale and design. J Card Fail. 2013;19(3):156-62. https://doi. org/10.1016/j.cardfail.2013.01.007.

11. Chan WX, Lin W, Wong RCC. Transitional care to reduce heart failure readmission rates in South East Asia. Card Fail Rev. 2016;2(2):85-9.

12. Jeon Y-H, Kraus SG, Jowsey T, Glasgow NJ. The experience of living with chronic heart failure: a narrative review of qualitative studies. BMC Health Serv Res. 2010;10(1):77. http://bmchealthservres.biomedcentral.com/articles/10.1186/1472-6963-10-77.

13. Evangelista LS, Shinnick MA. What do we know about adherence and self-care? J Cardiovasc Nurs. 2008;23(3):250.

14. Antonovsky A. The structure and properties of the sense of coherence scale. Soc Sci Med. 1993;36(6):725-33.

15. Eriksson M. The sense of coherence in the salutogenic model of health. The handbook of salutogenesis. Berlin: Springer; 2017. p. 91-5.

16. Antonovsky A. Health, stress, and coping. London: Jossey-Bass; 1979.

17. Mittelmark MB, Sagy S, Eriksson M, Bauer GF, Pelikan JM, Lindström B, et al. The handbook of salutogenesis. Berlin: Springer; 2017.

18. Sullivan GC. Evaluating Antonovsky's salutogenic model for its adaptability to nursing. J Adv Nurs. 1989;14(4):336-42. 
19. Nesbitt BJ, Heidrich SM. Sense of coherence and illness appraisal in older women's quality of life. Res Nurs Health. 2000;23(1):25-34.

20. Volanen S, Suominen S, Lahelma E, Koskenvuo M, Silventoinen K. Negative life events and stability of sense of coherence: a five-year follow-up study of Finnish women and men. Scand J Psychol. 2007;48(5):433-41.

21. Eriksson M. Unravelling the mystery of salutogenesis: the evidence base of the salutogenic research as measured by Antonovsky's sense of coherence scale. Turku: Åbo Akademi; 2007.

22. Lainscak M, Keber I. Patient's view of heart failure: from the understanding to the quality of life. Eur J Cardiovasc Nurs. 2003;2(4):275-81.

23. Mahoney JS. An ethnographic approach to understanding the illness experiences of patients with congestive heart failure and their family members. Heart Lung. 2001;30(6):429-36. http://www.ncbi.nlm.nih. gov/pubmed/11723447.

24. Currie K, Strachan PH, Spaling M, Harkness K, Barber D, Clark AM. The importance of interactions between patients and healthcare professionals for heart failure self-care: a systematic review of qualitative research into patient perspectives. Eur J Cardiovasc Nurs. 2015;14(6):525-35. http://journals.sagepub.com/doi/10.1177/1474515114547648.

25. Yancy CW, Jessup M, Bozkurt B, Butler J, Casey DE, Colvin MM, et al. 2017 ACC/AHA/HFSA focused update of the 2013 ACCF/AHA Guideline for the Management of Heart Failure: a report of the American College of Cardiology/American Heart Association Task Force on Clinical Practice Guidelines and the Heart Failure Society of America. Circulation. 2017;136(6):e137-61.

26. Colucci WS, Gottlieb SS, Yeon SB. Use of diuretics in patients with heart failure. UpToDate. 2019. https://www.uptodate.com/contents/use-of-diuretics-in-patients-with-heart-failure?search=diureticin heartfailure \&source=search_result\&selectedTitle=1 $\sim 150 \&$ usage_type $=$ default\&display_rank=1\#H1 .

27. Lainscak M, Blue L, Clark AL, Dahlstrom U, Dickstein K, Ekman I, et al. Self-care management of heart failure: practical recommendations from the patient care committee of the heart failure association of the European Society of Cardiology. Eur $\mathbf{J}$ Heart Fail. 2011;13(2):115-26.

28. Ma H, Lum C, Woo J. Readmission of patients with congestive heart failure: the need for focused care. Asian J Gerontol. 2006;1(1):59-60.

29. Phillips CO, Wright SM, Kern DE, Singa RM, Shepperd S, Rubin HR. Comprehensive discharge planning with postdischarge support for older patients with congestive heart failure: a metaanalysis. JAMA. 2004;291(11):1358-67.

30. van der Wal MHL, Jaarsma T. Adherence in heart failure in the elderly: problem and possible solutions. Int J Cardiol. 2008;125(2):203-8.

31. Zhang Y, Wu S-H, Fendrick AM, Baicker $\mathrm{K}$. Variation in medication adherence in heart failure.
JAMA Intern Med. 2013;23173(6):468-70. https:// www.ncbi.nlm.nih.gov/pmc/articles/PMC3624763/ pdf/nihms412728.pdf.

32. Horowitz CR, Rein SB, Leventhal H. A story of maladies, misconceptions and mishaps: effective management of heart failure. Soc Sci Med. 2004;58(3):631-43.

33. Nordfonn OK, Morken IM, Bru LE, Huseb $\varnothing$ AML. Patients' experience with heart failure treatment and self-care - a qualitative study exploring the burden of treatment. J Clin Nurs. 2019;28(9-10):1782-93.

34. Greenberg RN. Overview of patient compliance with medication dosing: a literature review. Clin Ther. 1984;6(5):592-9.

35. Pullar T, Birtwell AJ, Wiles PG, Hay A, Feely MP. Use of a pharmacologic indicator to compare compliance with tablets prescribed to be taken once, twice, or three times daily. Clin Pharmacol Ther. 1988;44(5):540-5.

36. Udelson JE, Pressler SJ, Sackner-Bernstein J, Massaro J, Ordronneau P, Lukas MA, et al. Adherence with once daily versus twice daily carvedilol in patients with heart failure: the compliance and quality of life study comparing once-daily controlled-release carvedilol $\mathrm{CR}$ and twice-daily immediate-release carvedilol IR in patients with heart failure (CASPER) trial. J Card Fail. 2009;15(5):385-93. https://doi.org/10.1016/j. cardfail.2008.12.010.

37. Claxton AJ, Cramer J, Pierce C. A systematic review of the associations between dose regimens and medication compliance. Clin Ther. 2001;23(8):1296-310.

38. Andrews AM, Russell CL, Cheng AL. Medication adherence interventions for older adults with heart failure: a systematic review. J Gerontol Nurs. 2017;43(10):37-45.

39. Molloy GJ, O'Carroll RE, Witham MD, McMurdo MET. Interventions to enhance adherence to medications in patients with heart failure a systematic review. Circ Hear Fail. 2012;5(1):126-33.

40. Bergman E, Malm D, Ljungquist B, Berterö C, Karlsson J. Meaningfulness is not the most important component for changes in sense of coherence; 2012.

41. Sua YS, Jiang Y, Thompson DR, Wang W. Effectiveness of mobile phone-based selfmanagement interventions for medication adherence and change in blood pressure in patients with coronary heart disease: a systematic review and meta-analysis. Eur $\mathrm{J}$ Cardiovasc Nurs. 2020;19(3):192-200.

42. Goldstein CM, Gathright EC, Dolansky MA, Gunstad J, Sterns A, Redle JD, et al. Randomized controlled feasibility trial of two telemedicine medication reminder systems for older adults with heart failure. J Telemed Telecare. 2014;20(6):293-9.

43. Gandapur Y, Kianoush S, Kelli HM, Misra S, Urrea $\mathrm{B}$, Blaha MJ, et al. The role of mHealth for improving medication adherence in patients with cardiovascular 
disease: a systematic review. Eur Heart J Qual Care Clin Outcomes. 2016;2(4):237-44.

44. McMurray JJV, Adamopoulos S, Anker SD, Auricchio A, Böhm M, Dickstein K, et al. ESC guidelines for the diagnosis and treatment of acute and chronic heart failure 2012. Eur J Heart Fail. 2012;14(8):803-69. http://doi.wiley.com/10.1093/ eurjhf/hfs 105 .

45. Colin-Ramirez E, Ezekowitz JA. Salt in the diet in patients with heart failure: what to recommend. Curr Opin Cardiol. 2016;31(2):196-203.

46. Arcand J, Ivanov J, Sasson A, Floras V, Al-Hesayen A, Azevedo E, et al. A high-sodium diet is associated with acute decompensated heart failure in ambulatory heart failure patients: a prospective follow-up study. Am J Clin Nutr. 2011;93:332-7.

47. Song EK, Moser DK, Dunbar SB, Pressler SJ, Lennie TA. Dietary sodium restriction below 2 gram per day predicted shorter event-free survival in patients with mild heart failure. Eur J Cardiovasc Nurs. 2014;13(6):541-8.

48. Butler J, Papadimitriou L, Georgiopoulou V, Skopicki H, Dunbar S, Kalogeropoulos A. Comparing sodium intake strategies in heart failure: rationale and design of the PROHIBIT sodium (PRevent adverse Outcomes in Heart failure By LimITing Sodium) study. Circ Heart Fail. 2015;8(3):636-45.

49. Ezekowitz JA, Meara EO, Mcdonald MA, Abrams H, Chan M, Ducharme A, et al. 2017 Comprehensive update of the Canadian Cardiovascular Society Guidelines for the management of heart failure. Can J Cardiol. 2017;33(11):1342-433.

50. Yancy CW, Jessup M, Bozkurt B, Butler J, Casey DE, Drazner MH, et al. 2013 ACCF/AHA guideline for the management of heart failure: a report of the American College of Cardiology Foundation/ American Heart Association Task Force on practice guidelines. Circulation. 2013;128(16):240-327.

51. Ponikowski P, Voors AA, Anker SD, Bueno H, Cleland JGF, Coats AJS, et al. 2016 ESC guidelines for the diagnosis and treatment of acute and chronic heart failure. Eur Heart J. 2016;37(27):2129-200.

52. Konerman MC, Hummel SL. Sodium restriction in heart failure: benefit or harm? Curr Treat Options Cardiovasc Med. 2014;16(2):286.

53. Colin-Ramirez E, McAlister FA, Zheng Y, Sharma S, Armstrong PW, Ezekowitz JA. The long-term effects of dietary sodium restriction on clinical outcomes in patients with heart failure. The SODIUM-HF (Study of Dietary Intervention under $100 \mathrm{mmol}$ in Heart Failure): a pilot study. Am Heart J. 2015;169(2):274281.e1. https://doi.org/10.1016/j.ahj.2014.11.013.

54. Paterna S, Gaspare P, Fasullo S, Sarullo FM, Di Pasquale P. Normal-sodium diet compared with lowsodium diet in compensated congestive heart failure: is sodium an old enemy or a new friend? Clin Sci. 2008;114(3-4):221-30.

55. Horwitz L, Krumholz H, Hunt SA, Yeon SB. Heart failure self-management. UpToDate.
2019. https://www.uptodate.com/contents/ heart-failure-self-management.

56. Dunbar SB, Clark PC, Reilly CM, Gary RA, Smith A, McCary F, et al. A trial of family partnership and education interventions in heart failure. J Card Fail. 2012;23(1):1-7.

57. Riegel B, Lee S, Hill J, Daus M, Baah FO, Wald JW, et al. Patterns of adherence to diuretics, dietary sodium and fluid intake recommendations in adults with heart failure. Hear Lung. 2019;48(3):179-85.

58. Colin-Ramirez E, McAlister FA, Woo E, Wong N, Ezekowitz JA. Association between self-reported adherence to a low-sodium diet and dietary habits related to sodium intake in heart failure patients. J Cardiovasc Nurs. 2015;30(1):58-65.

59. Chung ML, Lennie TA, de Jong M, Wu JR, Riegel B, Moser DK. Patients differ in their ability to selfmonitor adherence to a low-sodium diet versus medication. J Card Fail. 2008;14(2):114-20.

60. Bentley B, De Jong MJ, Moser DK, Peden AR. Factors related to nonadherence to low sodium diet recommendations in heart failure patients. Eur J Cardiovasc Nurs. 2005;4(4):331-6.

61. Ong SF, Foong PPM, Seah JSH, Elangovan L, Wang W. Learning needs of hospitalized patients with heart failure in Singapore: a descriptive correlational study. J Nurs Res. 2018;26(4):250-9.

62. Kuehneman T, Saulsbury D, Splett P, Chapman DB. Demonstrating the impact of nutrition intervention in a heart failure program. J Am Diet Assoc. 2002;102(12):1790-4.

63. Zeng W, Chia SY, Chan YH, Tan SC, Low EJH, Fong MK. Factors impacting heart failure patients' knowledge of heart disease and self-care management. Proc Singapore Healthc. 2017;26(1):26-34.

64. Wilson DK, Ampey-Thornhill G. The role of gender and family support on dietary compliance in an African American adolescent hypertension prevention study. Ann Behav Med. 2001;23(1):59-67.

65. Johansson P, Van Der Wal MHL, Strömberg A, Waldréus N, Jaarsma T. Fluid restriction in patients with heart failure: how should we think? Eur J Cardiovasc Nurs. 2016;15(5):301-4.

66. Holst M, Strömberg A, Lindholm M, Willenheimer R. Liberal versus restricted fluid prescription in stabilised patients with chronic heart failure: result of a randomised cross-over study of the effects on healthrelated quality of life, physical capacity, thirst and morbidity. Scand Cardiovasc J. 2008;42(5):316-22.

67. Travers B, O'Loughlin C, Murphy NF, Ryder M, Conlon $\mathrm{C}$, Ledwidge $\mathrm{M}$, et al. Fluid restriction in the management of decompensated heart failure: no impact on time to clinical stability. J Card Fail. 2007; 13(2):128-32.

68. Hooper L, Abdelhamid A, Attreed NJ, Campbell WW, Channell AM, Chassagne P, et al. Clinical symptoms, signs and tests for identification of impending and current water-loss dehydration in older people. Cochrane Database Syst Rev 2015;(4). 
69. Chaudhry SI, Wang Y, Concato J, Gill TM, Krumholz HM. Patterns of weight change preceding hospitalization for heart failure. Circulation. 2007;116(14):1549-54.

70. Riegel B, Lee CS, Dickson VV, Carlson B. An update on the self-care of heart failure index. J Cardiovasc Nurs. 2009;24(6):485-97.

71. Malhotra C, Cheng Sim Wong G, Tan BC, Ng CSH, Lee NC, Lau CSL, et al. Living with heart failure: perspectives of patients from Singapore. Proc Singapore Healthc. 2016;25(2):92-7.

72. Clark AM, Spaling M, Harkness K, Spiers J, Strachan PH, Thompson DR, et al. Determinants of effective heart failure self-care: a systematic review of patients' and caregivers' perceptions. Heart. 2014;100(9):716-21.

73. Costello JA, Boblin S. What is the experience of men and women with congestive heart failure? Can J Cardiovasc Nurs. 2004;14(3):9-20. https:// www.scopus.com/inward/record.uri?eid=2-s2.07244224845\&partnerID=40\&md5=bcd548737deab $960031324587433 \mathrm{e} 477$.

74. Vaughan Dickson V, Lee CS, Riegel B. How do cognitive function and knowledge affect heart failure self-care? J Mix Methods Res. 2011;5(2):167-89.

75. Moser DK, Doering LV, Chung ML. Vulnerabilities of patients recovering from an exacerbation of chronic heart failure. Am Heart J. 2005;150(5):984. e7-13.

76. Miller CL. Cue sensitivity in women with cardiac disease. Prog Cardiovasc Nurs. 2000;15(3):82-9.

77. Patel H, Shafazand M, Schaufelberger M, Ekman I. Reasons for seeking acute care in chronic heart failure. Eur J Heart Fail. 2007;9(6-7):702-8.

78. Alves TCTF, Rays J, Fráguas R Jr, Wajngarten M, Meneghetti JC, Prando S, et al. Localized cerebral blood flow reductions in patients with heart failure: a study using 99mTc-HMPAO SPECT. J Neuroimaging. 2005;15(2):150-6.

79. Woo MA, Macey PM, Fonarow GC, Hamilton MA, Harper RM. Regional brain gray matter loss in heart failure. J Appl Physiol. 2003;95(2):677-84.

80. Moser DK, Dickson V, Jaarsma T, Lee C, Stromberg A, Riegel B. Role of self-care in the patient with heart failure. Curr Cardiol Rep. 2012;14(3):265-75.

81. Jurgens CY, Hoke L, Byrnes J, Riegel B. Why do elders delay responding to heart failure symptoms? Nurs Res. 2009;58(4):274-82. https:// www.scopus.com/inward/record.uri?eid=2-s2.0$68349095171 \&$ doi $=10.1097 \%$ FNNR.0b013e3181 ac $1581 \&$ partnerID $=40 \&$ md5=6da 4 adfddb $8 b 1 \mathrm{dc} 40$ 06b92375b216525.

82. Creber RMM, Hickey KT, Maurer MS. Gerontechnologies for older patients with heart failure: what is the role of samrtphones, tablets, and remote monitoring devices in improving symptom monitoring and self-care management? Curr Cardiovasc Risk Rep. 2016;10(10):1-15.

83. Scherr D, Kastner P, Kollmann A, Hallas A, Auer J, Krappinger $\mathrm{H}$, et al. Effect of home-based tele- monitoring using mobile phone technology on the outcome of heart failure patients after an episode of acute decompensation: randomized controlled trial. J Med Internet Res. 2009;11(3):1-12.

84. Inglis SC, Clark RA, McAlister FA, Ball J, Lewinter C, Cullington D, et al. Structured telephone support or telemonitoring programmes for patients with chronic heart failure. Cochrane Database Syst Rev. 2010;4(8):CD007228

85. Seto E, Leonard KJ, Cafazzo JA, Barnsley J, Masino C, Ross HJ. Mobile phone-based telemonitoring for heart failure management: a randomized controlled trial. J Med Internet Res. 2012;14(1):1-14.

86. Chaudhry SI, Mattera JA, Curtis JP, Spertus JA, Herrine J, Lin Z, et al. Telemonitoring in patients with heart failure. N Engl J Med. 2011;364(24):2301-9.

87. Zan S, Agboola S, Moore SA, Parks KA, Kvedar JC, Jethwani K. Patient engagement with a mobile webbased telemonitoring system for heart failure selfmanagement: a pilot study. JMIR Mhealth Uhealth. 2015;3(2):e33.

88. O'Connor CM, Whellan DJ, Lee KL, Keteyian SJ, Cooper LS, Ellis SJ, et al. Efficacy and safety of exercise training in patients with chronic heart failure: HF-ACTION randomized controlled trial. JAMA. 2009;301(14):1439-50.

89. Taylor RS, Sagar VA, Davies EJ, Briscoe S, Coats AJS, Dalal $\mathrm{H}$, et al. Exercise-based rehabilitation for heart failure. Cochrane Database Syst Rev. 2014;2014(4):CD003331.

90. Pearson MJ, Smart NA. Exercise therapy and autonomic function in heart failure patients: a systematic review and meta-analysis. Heart Fail Rev. 2018;23(1):91-108.

91. Suskin N, Sheth T, Negassa A, Yusuf S. Relationship of current and past smoking to mortality and morbidity in patients with left ventricular dysfunction. J Am Coll Cardiol. 2001;37(6):1677-82. https://doi. org/10.1016/S0735-1097(01)01195-0.

92. Sidorenkov O, Nilssen O, Nieboer E, Kleshchinov N, Grjibovski AM. Premature cardiovascular mortality and alcohol consumption before death in Arkhangelsk, Russia: an analysis of a consecutive series of forensic autopsies. Int J Epidemiol. 2011;40(6):1519-29.

93. Lightwood J, Fleischmann KE, Glantz SA. Smoking cessation in heart failure: it is never too late. J Am Coll Cardiol. 2001;37(6):1683-4. https://doi. org/10.1016/S0735-1097(01)01188-3.

94. Heart Failure Society of America. Nonpharmacologic management and health care maintenance in patients with chronic heart failure. J Card Fail. 2006;12(1):29-37.

95. Aguilar D, Skali H, Moyé LA, Lewis EF, Gaziano JM, Rutherford JD, et al. Alcohol consumption and prognosis in patients with left ventricular systolic dysfunction after a myocardial infarction. J Am Coll Cardiol. 2004;43(11):2015-21.

96. Salisbury AC, House JA, Conard MW, Krumholz HM, Spertus JA. Low-to-moderate alcohol intake 
and health status in heart failure patients. J Card Fail. 2005;11(5):323-8.

97. O’Keefe JH, Bhatti SK, Bajwa A, DiNicolantonio JJ, Lavie CJ. Alcohol and cardiovascular health: the dose makes the poison...or the remedy. Mayo Clin Proc. 2014;89(3):382-93. https://doi.org/10.1016/j. mayocp.2013.11.005.

98. Powell L, Calvin J, Richardson D, Janssen I, de Mendes LC, Flynn K, et al. Self-management counseling in patients with heart failure: the heart failure adherence and retention randomized behavioral trial. JAMA. 2010;304:1331-8. http://onlinelibrary.wiley.com/o/cochrane/clcentral/articles/813/ CN-00762813/frame.html.

99. Shao J, Chang A, Edwards H, Shyu Y, Chen S. A randomized controlled trial of self-management programme improves health-related outcomes of older people with heart failure. J Adv Nurs. 2013;69:245869. http://onlinelibrary.wiley.com/o/cochrane/clcentral/articles/850/CN-00987850/frame.html.

100. Smeulders E, Haastregt J, Ambergen T, JanssenBoyne J, Eijk J, Kempen G. The impact of a selfmanagement group programme on health behaviour and healthcare utilization among congestive heart failure patients. Eur J Heart Fail. 2009;11:609-16. http://onlinelibrary.wiley.com/o/cochrane/clcentral/ articles/763/CN-00720763/frame.html.

101. Smeulders E, Haastregt J, Ambergen T, UszkoLencer N, Janssen-Boyne J, Gorgels A, et al. Nurseled self-management group programme for patients with congestive heart failure: randomized controlled trial. J Adv Nurs. 2010;66:1487-99. http://onlinelibrary.wiley.com/o/cochrane/clcentral/articles/016/ CN-00773016/frame.html.

102. Dracup K, Evangelista LS, Hamilton MA, Erickson V, Hage A, Moriguchi J, et al. Effects of a homebased exercise program on clinical outcomes in heart failure. Am Heart J. 2007;154(5):877-83.

103. Yu DSF, Thompson DR. What makes a disease management programme for heart failure different: results of a meta-regression analysis. Int $\mathrm{J}$ Cardiol. 2008;125:S45-6.

104. Boren SA, Wakefield BJ, Gunlock TL, Wakefield DS. Heart failure self-management education: a systematic review of the evidence. Int J Evid Based Healthc. 2009;7(3):159-68.

105. Boyde M, Peters R, New N, Hwang R, Ha T, Korczyk D. Self-care educational intervention to reduce hospitalisations in heart failure: a randomised controlled trial. Eur J Cardiovasc Nurs. 2018;17(2):178-85.

106. Boyde M, Peters R, Hwang R, Korczyk D, Ha T, New $N$. The self-care educational intervention for patients with heart failure. J Cardiovasc Nurs. 2017;32(2):165-70. http://insights.ovid.com/crossr ef?an=00005082-201703000-00012.

107. Arlinghaus KR, Johnston CA. Advocating for behavior change with education. Am J Lifestyle Med. 2018;12(2):113-6.

108. Rozanski A, Blumenthal JA, Davidson KW, Saab PG, Kubzansky L. The epidemiology, pathophysiol- ogy, and management of psychosocial risk factors in cardiac practice: the emerging field of behavioral cardiology. J Am Coll Cardiol. 2005;45(5):637-51. https://doi.org/10.1016/j.jacc.2004.12.005.

109. Williams RB. Psychosocial and biobehavioral factors and their interplay in coronary heart disease. Annu Rev Clin Psychol. 2008;4:349-65.

110. Samartzis L, Dimopoulos S, Tziongourou M, Nanas S. Effect of psychosocial interventions on quality of life in patients with chronic heart failure: a metaanalysis of randomized controlled trials. J Card Fail. 2013;19(2):125-34. https://doi.org/10.1016/j. cardfail.2012.12.004.

111. Thompson DR, Ski CF. Psychosocial interventions in cardiovascular disease-what are they? Eur J Prev Cardiol. 2013;20(6):916-7. http://cpr.sagepub.com/ lookup/doi/10.1177/2047487313494031.

112. Lane D, Chong A, Lip G. Cochrane review psychological interventions for depression in HF. 2005;(1). file:///C:/Users/acer/Documents/Mendeley Desktop/ Cochrane review psychological interventions for depression in HF.pdf.

113. Klainin-Yobas P, Ng SH, Stephen PDM, Lau Y. Efficacy of psychosocial interventions on psychological outcomes among people with cardiovascular diseases: a systematic review and meta-analysis. Patient Educ Couns. 2016;99(4):512-21. https://doi. org/10.1016/j.pec.2015.10.020.

114. Jiang Y, Shorey S, Seah B, Chan W, Tam WWS, Wang W. The effectiveness of psychological interventions on self-care, psychological and health outcomes in patients with chronic heart failure-a systematic review and meta-analysis. Int J Nurs Stud. 2018;78:16-25. https://doi.org/10.1016/j. ijnurstu.2017.08.006.

115. Gustavsson A, Bränholm IB. Experienced health, life satisfaction, sense of coherence, and coping resources in individuals living with heart failure. Scand J Occup Ther. 2003;10(3):138-43.

116. Gallagher R. Self management, symptom monitoring and associated factors in people with heart failure living in the community. Eur $\mathrm{J}$ Cardiovasc Nurs. 2010;9(3):153-60. https://doi.org/10.1016/j. ejcnurse.2009.12.006

117. Ferreira VMP, Silva LN, Furuya RK, Schmidt A, Rossi LA, Dantas RAS. Self-care, sense of coherence and depression in patients hospitalized for decompensated heart failure. Rev da Esc Enferm. 2015;49(3):387-93.

118. Ekman I, Fagerberg B, Lundman B. Health-related quality of life and sense of coherence among elderly patients with severe chronic heart failure in comparison with healthy controls. Heart Lung. 2002;31(2):94-101.

119. Chow CK, Ariyarathna N, Islam SMS, Thiagalingam A, Redfern J. mHealth in cardiovascular health care. Hear Lung Circ. 2016;25(8):802-7. https://doi. org/10.1016/j.hlc.2016.04.009.

120. Dansky KH, Vasey J, Bowles K. Impact of telehealth on clinical outcomes in patients with heart failure. 
Clin Nurs Res. 2008;17(3):182-99. http://journals. sagepub.com/doi/10.1177/1054773808320837.

121. Arora S, Peters AL, Burner E, Lam CN, Menchine M. Trial to examine text message-based mhealth in emergency department patients with diabetes (TExT-MED): a randomized controlled trial. Ann Emerg Med. 2014;63(6):745-754.e6. https://doi. org/10.1016/j.annemergmed.2013.10.012.

122. Buck H, Pinter A, Poole E, Boehmer J, Foy A, Black $\mathrm{S}$, et al. Evaluating the older adult experience of a web-based, tablet-delivered heart failure self-care program using gerontechnology principles. Geriatr Nurs (Minneap). 2017;38:537-41. https://doi. org/10.1016/j.gerinurse.2017.04.001.
123. Creber RMM, Maurer MS, Reading M, Hickey KT, Iribarren S. Review and analysis of existing mobile phone apps to support heart failure symptom monitoring and self-care management using the mobile application rating scale (MARS). JMIR mHealth uHealth. 2016;4(2):e74.

124. Athilingam P, Jenkins B, Johansson M, Labrador M. A mobile health intervention to improve selfcare in patients with heart failure: pilot randomized control trial. JMIR Cardiol. 2017;1(2):e3.

Open Access This chapter is licensed under the terms of the Creative Commons Attribution 4.0 International License (http://creativecommons.org/licenses/by/4.0/), which permits use, sharing, adaptation, distribution and reproduction in any medium or format, as long as you give appropriate credit to the original author(s) and the source, provide a link to the Creative Commons license and indicate if changes were made.

The images or other third party material in this chapter are included in the chapter's Creative Commons license, unless indicated otherwise in a credit line to the material. If material is not included in the chapter's Creative Commons license and your intended use is not permitted by statutory regulation or exceeds the permitted use, you will need to obtain permission directly from the copyright holder. 